\title{
Aggressiva talgoxar Parus major: utsvultna fåglar eller tillhörande en annan population?
}

\author{
Aggressive Great Tits Parus major: starved birds or belonging to a different \\ population?
}

HANS RYTTMAN

\begin{abstract}
During autumn 2016, bird ringing stations in east Sweden observed Great Tits Parus major with extremely aggressive behaviour. They attacked smaller birds such as Goldcrests Regulus regulus, killed them and ate the brain or the content of the belly. I examine with data from Ottenby Bird Observatory two explanations: the birds were exhausted after migration and very hungry or they were birds from an eastern population where aggressive be-

first explanation was not supported. Unfortunately, wing length cannot be used to differentiate between Swedish and more eastern populations so also the second explanation could not be supported. However, Great Tits from eastern parts of north Europe moult their alula earlier than birds from Sweden. The next time aggressive Great Tits are observed, bird ringers should check the moulting stage of the alula in order to determine their origin.
\end{abstract} haviour has been suggested to be more common. Fat index and body mass did not indicate low energy stores and the weather was stable with wind from the east so the

Hans Ryttman.

Email: hans.ryttman@telia.com

Under hösten 2016 kom ett stort inflöde av talgoxar Parus major till fågelstationer på den svenska ostkusten. Många av dessa talgoxar uppvisade ett mycket aggressivt beteende. Vissa talgoxar dödade andra fåglar, som oftast var mindre än dem själva, genom att hacka på den mindre fågelns hjässa så att de kom åt hjärnan. Ringmärkare observerade också talgoxar som angrep mindre fåglar utanför näten och dödade dem genom att just hacka sönder hjässan. Fåglar som hängde $i$ näten nära talgoxarna kunde också få sina bukar upphackade varefter talgoxen åt av innehållet (Douhan 2016). En möjlig orsak till detta beteende är att många av de inkomna talgoxarna var uthungrade och snabbt behövde fylla på sina energidepåer.

Larsson (2015) har beskrivit hur magra talgoxar visat aggressivt beteende under två dagars ringmärkning (13-14 oktober 2014) på Utklippan i Blekinge. De fångade talgoxarna, både hanar och honor, vägde signifikant mindre i jämförelse med fångade talgoxar de sju föregående åren. Larsson fann också döda talgoxar i näten och även på marken, vilket indikerar att många talgoxar varit helt utmattade. Larsson (2015) föreslog att det troligen berodde på att talgoxarna som kom till Utklippan den 13-14 oktober hade flugit i regn och i motvind så att flygtiden från Baltikum tagit 15 upptill 20 timmar, vilket kunde förklara de låga vikterna på fåglarna.

Förhållandena var helt annorlunda 2016 då vädret under hela oktober oftast var klart och att fåglarna som troligen kom öster ifrån, hade en stadig medvind så gott som hela månaden (SMHI 2016). Några utmattade talgoxar i näten eller för övrigt sågs varken på Svenska Högarna eller vid Ottenby (Bill Douhan, muntligen, Magnus Hellström, i e-brev). Trots det gynnsamma vädret kunde naturligtvis talgoxarna ändå vara uthungrade på grund av födobrist där fåglarna kom ifrån. En och annan av de fåglar som talgoxarna lyckades döda utanför näten kan naturligtvis ha varit utmattade, likt den brunsångare Phyllocopus fuscatus som dödades av en talgoxe på Öland (Christian Cederroth, muntligen).

Detta aggressiva beteende hos talgoxar observeras relativt sällan i Sverige. Douhan (2016), med 40 års erfarenhet av ringmärkning på Svenska Högarna, minns att talgoxarna som ringmärktes 1976 och 1977 hade samma aggressiva beteende att hacka ihjäl mindre fåglar. Däremot såg han aldrig att talgoxarna flög efter eller dödade fåglar utanför nätet som några talgoxar gjorde under hösten 2016 (Douhan 2016).

En annan möjlighet är att talgoxarna kom från en annan population där det aggressiva beteendet är vanligare. Cramp (1989) nämner att ryska talgoxar visat ett aggressivt beteende men orsaken till beteendet nämns eller diskuteras inte. Estok et al. (2010) har beskrivit hur talgoxar i Ungern angripit dvärgfladdermöss och på liknande sätt dödat dessa genom att hacka sönder hjässan.

En möjlighet att studera om det rör sig om utsvultna 
fåglar eller fåglar från en annan population med andra vanor, som kan vara mest trolig, är att jämföra talgoxar från två år (med och utan den beskrivna aggressiviteten) vad gäller fettstatus, vikt och vinglängd, där det senare måttet kan vara kopplat till populationstillhörighet.

Vid Ottenby fågelstation insamlades data på fett, vinge och vikt på alla talgoxar märkta höstarna 2015 och 2016. Inget aggressivt beteende observerades 2015 men det var vanligt förekommande 2016. Antalet talgoxar skiljde sig mellan åren. Under 2015 var antalet 82 och under 2016 hela 1170 . Mängden synligt fett klassades enligt en skala från 0 till 6 (Pettersson \& Hasselquist 1985). Fåglarna fångades mellan den 3 och 31 oktober båda åren, förutom en respektive två fåglar som fångades i september.

Proportion juvenila (10) och äldre (2+) fåglar mellan de två åren skilde sig inte signifikant åt (homogenitets-test, $\mathrm{Chi}^{2}=1,99$, NS). I analyserna har jag därför inte slagit ihop åldersklasserna. Eftersom det är en tydlig storleksskillnad mellan honor och hanar vad gäller både vikt $(0,5-1,0 \mathrm{~g})$ och vinglängd $(2,5 \mathrm{~mm})$ har dock jämförelserna mellan de två åren gjorts separat för respektive kön. Skillnader mellan åren testades med t-test.

Två signifikanta skillnader fanns mellan åren (Tabell 1). Honorna 2016 hade signifikant mindre fett än honorna 2015, även om värdena som sådana under 2016 inte var speciellt låga (2,5 på en skala från 0 till 6). Omvänt så vägde hanarna under 2016 mer än hanarna 2015.

Sammantaget tyder alltså inget $\mathrm{i}$ data från Ottenby på att 2016 års talgoxar var speciellt magra, inte heller i jämförelse med 2015. Hypotesen om att talgoxarnas angrepp och dödande av andra fåglar för att komma åt deras hjärna och maginnehåll för att snabbt få mer energi tycks alltså inte stämma.

De medelvikter som Larsson (2015) anger för Utklippans fångade talgoxar för åren 2007-2013 är lägre än de hos både 2015 och 2016 års talgoxar på Ottenby. Även de talgoxar som hade 0 i fettindex vid Ottenby $2016(\mathrm{n}=23$, ca $2 \%)$ vägde mer än de på Utklippan hösten 2014 (Larsson 2015). Hanarna med fett 0 vid Ottenby under hösten 2016 vägde 16,4 g ( $n=7)$ i jämförelse med 15,8 g (n=73) hos samtliga hanar på Utklippan. För honorna var motsvarande värden 15,2 g $(n=16)$ och $14,7(n=85)$. Även detta tyder på att talgoxarna vid Ottenby 2016 inte var speciellt magra eller utsvultna.

Den eventuella stress som födobrist i ursprungsområdet och/eller ansträngande flygningar skulle kunnat orsaka, kunde alltså inte verifieras för talgoxarna vid Ottenby, vilket är i kontrast till talgoxarna vid Utklippan 2014 (Larsson 2015). Att beteendet orsakats av stress då många individer finns på samma plats kan inte uteslutas, men är mindre trolig då antalet fångade talgoxar endast var dubbelt så många som fångats flera tidigare år (Ringmärkningscentralen i e-brev). Emellertid fångade Ottenby över 1000 talgoxar 1976. Ur Ottenbys dagbok (utdrag skickat i e-brev av Magnus Hellström) kan man läsa "Under oktober har sammanlagt närmare 1700 talgoxar ringmärkts. För så gott som samtliga av dessa har vingmått samt uppgifter om ruggning av handtäckare insamlats (JPN). ... Fåglarnas ostliga ursprung verifierades av en polskmärkt talgoxe. Liksom under fjolårets höstinvasion av mesar uppträd-

\begin{tabular}{lllrrr}
\hline & År Year & Medel Mean \pm se & $\mathrm{n}$ & $\mathrm{t}$ & $\mathrm{P}$ \\
\hline Honor Females & & & & & \\
Vikt Mass $(\mathrm{g})$ & 2015 & $16,7 \pm 0,22$ & 44 & & \\
& 2016 & $16,5 \pm 0,05$ & 695 & 0,19 & 0,29 \\
Fett Fat score & 2015 & $3,02 \pm 0,20$ & 44 & & \\
& 2016 & $2,52 \pm 0,06$ & 695 & 2,17 & 0,03 \\
Vinge Wing (mm) & 2015 & $75,3 \pm 0,22$ & 44 & & \\
& 2016 & $75,3 \pm 0,05$ & 695 & 0,19 & 0,85 \\
Hanar Males & & & & & \\
Vikt Mass (g) & 2015 & $17,2 \pm 0,19$ & 38 & & \\
& 2016 & $17,6 \pm 0,08$ & 472 & 1,99 & 0,047 \\
Fett Fat score & 2015 & $2,55 \pm 0,17$ & 38 & & \\
& 2016 & $2,63 \pm 0,06$ & 475 & 0,32 & 0,75 \\
Vinge Wing (mm) & 2015 & $77,9 \pm 0,24$ & 38 & & \\
& 2016 & $78,2 \pm 0,07$ & 474 & 0,44 & 0,66 \\
\hline
\end{tabular}

Tabell 1. Jämförelse mellan genomsnittlig ( \pm se) vikt, fettindex och vinglängd hos honor respektive hanar av talgoxe fångade vid Ottenby fågelstation år 2015 och 2016.

A comparison between female and male Great Tits average ( \pm se) body mass, fat index and wing length at Ottenby Bird Observatory in southeast Sweden in 2015 and 2016. 
de dessa ryska mesar som rena dödsskvadronerna, och talgoxarna sågs bl a attackera rödhake, gärdsmyg och kärrsnäppa(!)"

Vinglängdsskillnader kan ibland användas för att särskilja olika populationer men det fanns inga skillnader i vinglängd mellan åren vid Ottenby (Tabell 1). Pettersson (1981) har studerat tre populationers vinglängd. En östlig, som han särskilde genom att alulan ruggas tidigare i öster än i Sverige, en från Ottenby och en på en svensk inlandslokal på vintern (Tybble, Närke). Mellan dessa tre populationer fanns dock ingen vinglängdsskillnad. Avsaknaden av skillnad i vinglängd mellan de två åren på Ottenby är alltså $\mathrm{i}$ sig inte ett bevis för att inte olika populationer varit involverade.

Cramp (1989) skriver att ryska talgoxar kan uppvisa aggressiva beteenden vilket är intressant med tanke på att östliga populationer oftare flyttar öster om Östersjön. Detta visades av Pettersson (1981) då han fann att fler unga talgoxar hade bytt alula på en polsk fågelstation än på Ottenby. Estoks et al. (2010) iakttagelse av talgoxar som dödar fladdermöss i dvala kan också tänkas ha ett östligt ursprung. Om aggressiva talgoxar skulle dyka upp kommande år vore det lämpligt att studera alula-ruggningen för att bättre bedöma talgoxarnas populationstillhörighet. Inte minst vore det intressant att jämföra ruggningen hos individer med dokumenterat aggressivt beteende med förmodat icke-aggressiva individer.

\section{Referenser}

Cramp, S. (ed.) 1989. Handbook of the birds of Europe, the Middle East and North Africa. The birds of Western Palearctic. Vol. VI. Oxford Univ.Press, Oxford.

Douhan, B. 2016. Talgoxar på småfågeljakt. Fåglar i Uppland 43: 4-5.

Estok, P., Zsebok, S. \& Siemers, B. M. 2010. Great tits search for, catch, kill and eat hibernating bats. Biology Letters 6: 59-62.

Larsson, R. 2015. Tillfälligt inflöde av magra och aggressiva talgoxar Parus major under höstflyttning på Utklippan. Ornis Svecica 25: 109-118.

Pettersson, J. 1981. Ruggning och geografiskt ursprung hos talgoxe Parus major vid Ottenby. Vår Fågelvärld 40: 461466.

Pettersson, J. \& Hasselquist, D. 1985. Fat deposition and migration capacity of robins Erithacus rubecula and goldcrests Regulus regulus at Ottenby, Sweden. Ringing \& Migration 6: 66-76.

SMHI (2016). Månadens väder. http://www.smhi.se/klimat/ klimatet-da-och-nu/manadens-vader-och-vatten-sverige/ manadens-vader-i-sverige/oktober-2016-meteorologi-1.109914 (nedladdad 170807).

\section{Tack}

Ett stort tack till Magnus Hellström, Ottenby fågelstation, som tillhandahöll de talgoxdata som möjliggjorde studien. Tack också till Bill Douhan för värdefull information från Svenska Högarna samt tips om litteratur. Synpunkter från två anonyma granskare har varit värdefulla och förbättrat artikeln. Detta är meddelande nummer 304 från Ottenby Fågelstation.

\section{Summary}

During autumn 2016, several bird ringing stations in east Sweden, including Ottenby Bird Observatory, observed Great Tits Parus major with a rather extreme aggressive behaviour. The tits attacked smaller birds such as Goldcrests Regulus regulus, especially in the mistnets, by picking on the smaller birds head or on the belly. The Great Tits killed the birds and, if possible, ate the brain or the content of the belly.

This behaviour may indicate that the Great Tits were energetically exhausted and very hungry, which could be analysed by comparing body mass and fat scores of Great Tits from years with no observed killings to those of birds from 2016. An alternative explanation to the aggressive behaviour may be that the Great Tits in 2016 belonged to a different population, where this behaviour is more common.

Great Tits caught at Ottenby in $2015(\mathrm{n}=82)$ and $2016(n=1170)$ were compared regarding fat index, body mass and wing length (Table 1). The females from 2016 were leaner than those in 2016, although the birds from 2016 were not very lean as such ( 2.5 on a scale between 0 and 6). On the other hand, males in 2016 were heavier than in 2015. Thus, there were no strong indications that the aggressive behaviour from the Great Tits 2016 were due to low energy stores.

This is in contrast to the findings of Larsson (2015) who observed a similar aggressive behaviour of Great Tits in 2014 when the tits were strongly emaciated, probably caused by head-wind and rainy weather during their movement to Utklippan, another bird ringing station in southeast Sweden. The weather in autumn 2016 was quite different with mainly stable weather and wind from the east.

Alternatively, the birds in 2015 and 2016 could have belonged to different populations. Unfortunately, wing length (which did not differ between the two years) cannot be used to differentiate between Swedish and more eastern populations. However, Pettersson (1981) found that Great Tits from eastern parts of north Europe moult their alula earlier than birds from Sweden. The next time aggressive Great Tits are observed, bird ringers should check the moulting stage of the alula in order to have a hint of from which area the Great Tits come from. 